\title{
From 3D Content Models to HBIM for Conservation and Management of Built Heritage
}

\author{
Daniela Oreni \\ Politecnico di Milano, via Ponzio 31 \\ 20133 Milano, Italy \\ daniela.oreni@polimi.it
}

\begin{abstract}
The paper illustrates the possibility to move from a bi-dimensional geographic information system (GIS) and a 3D content model to an Historic Building Information Modelling (HBIM) for conservation and management of built heritage. This three dimensional solution is based on simplified parametric models, suitable for industrial elements and modern architecture, that can useful applied to heritage documentation and management of the data on conservation practices.

In order to motivate the opportunity in using this $3 \mathrm{D}$ object modelling instruments, in the paper were investigated the different bi-dimensional and three-dimensional typologies of representation, with the aim of identifying for each of them eventual lack in data relation, sharing, comparison and interrogation. Some case studies on brick vaults elements analysis show how could be implemented a HBIM for architectonic heritage in order to collect different kind of data on historical building (dimensional, geometrical, thematic, historical and constructive information).
\end{abstract}

Keywords: 3D content model, HBIM, GIS, geo-spatial data, built heritage, geometric analysis, survey interpretation, conservation, management.

\section{Introduction}

Conservation of built heritage is progressively linked to the regular maintenance of buildings, defining the preventing conservation as a real necessity in everyday practice. According to this aim, it's indeed necessary to have an instruments that allows to collect, compare and share all the data available on the dimension and state of conservation of the buildings (surveys, drawings, thematic and historical contents), and where to add future information about maintenance or restoration activities.

Consequently this paper discusses the possibility to move from traditional 2D constructive representation and $3 \mathrm{D}$ content models to an Historic Building Information Modelling (HBIM) in order to support preventive conservation, information sharing and knowledge dissemination of heritage, both for professional users, for institutions and experts involved in decision making process [1] [2]. Starting from the description of traditional 2D representation methodologies and 2D Geographic Information System for built heritage management and on geo-spatial 
data for the management of Cultural Heritage, at Italian and European level (section 2), section 2.4 gives a brief overview on three-dimensional content models. Through the exposition of some case studies, section 3 illustrates the use of BIM solution for the documentation and management of architectonic heritage and shows the differences between this kind of models and traditional ones.

\section{From Traditional Representation of Architectonic Heritage to 3D Content Models for Heritage Documentation and Management}

\subsection{Two-Dimensional Constructive Representation for Conservation Projects}

Survey of historic architecture and its elements requires methods of data collection and representation able to describe the building in a capillary manner, without arbitrarily selection of information [3]. The objective is infact to make survey an important instrument of knowledge and a support for all subsequent thematic analysis and diagnostic investigation, essential for the maintenance program and the project of conservation of the building.

Even though literature refers many interesting examples of 3D models for restoration, is still in use among the professionals, architects and experts the use of bidimensional representations of the buildings. There are multiple reasons about the difficulties in using 3D models for conservation analysis and projects: first of all the difficulties in mapping map areas (i.e. materials, state of conservation and deterioration, cracks) on 3D surfaces and in calculating the regions of intervention, with the final aim to value the cost of the whole process of conservation. Secondly there are some obstacles due to the use of different software for 3D modelling: the cost of them, the in-development of open source software, the question of formats of interchange, the interoperability and so on. All these reasons still caused the distance between academic research on 3D modelling for built heritage and application in everyday construction practice.

Usually in conservation field, beside of traditional 2D representation (plans, fronts and sections) a method of survey and cataloguing of data and measurements is used, called "box-system" approach [4]. It's a method of two-dimensional representation but oriented to a three-dimensional analysis and interpretation of the buildings and of their spaces. Infact, similarly to the method of Raumbuch, useful to analyse and manage buildings, developed in the German during the 90s of the twentieth century [5], the method of "box system" wants a gradual subdivision and coding of a complex architecture in parts. These parts must be identified by type and construction history (individual buildings, rooms, inner sides of a room, floor, ceiling, wall side, constructive elements) and the data must be represented in the form of "boxes" for each basic unit (Fig. 1).

On one hand this method allows to organise and represent all the measures in a coordinated and concise manner, facilitating comparative reading of the data and their future implementation. On the other hand it allows a continuous transition in scale 
between the survey of the whole architectural complex and its elements, enabling to cross data at different levels of detail and to support the next phase of interpretive reading of information. This method is similar to the traditional representation of architecture that uses combination of plans, sections and fronts: technological elements are thus not represented as single units but they are interconnected, forming a complex organism such as an architectural monument.
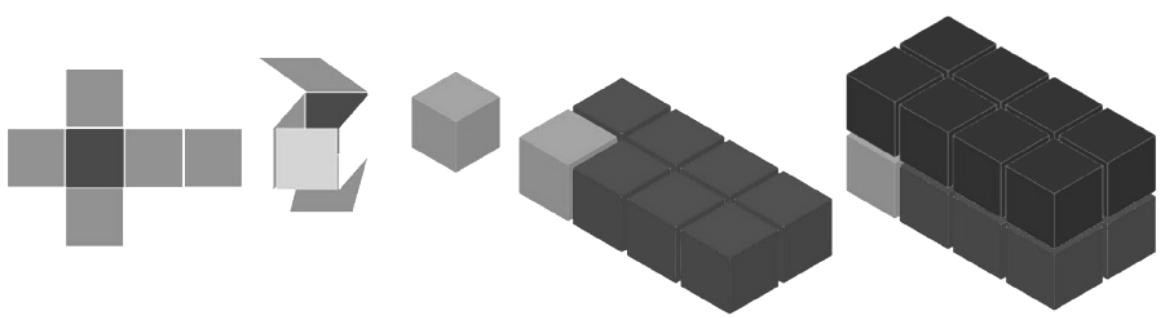

Fig. 1. "Box-system" as a tool for spatial data organisation. The survey of every room is connected to the other in a unique coordinate reference system. From left to right: the process of 3D interpretation and analysis of data survey of the building, starting from a twodimensional representation (box system) of each room.

This method both supports a systematic reading of all the geometrical, structural and material aspects that characterize the various parts of the building, and allows to collect other useful contributions to completely describe the architecture: the metric and photographic survey [6], archival, historic and stratigraphic data, pathologies of degradation, crack investigations and the results of diagnostic and instrumental analysis.

The contribution of the method "box system" does not end in a better organization and description of data survey but it provides an important support for the planning and implementation of maintenance and conservation projects, allowing also to check the interactions between the various technology components of the building. This method of representation and subdivision a building in parts, can be also well managed within a geographical information system (GIS) for the cataloguing, documentation and management of the data restoration process[7], promoting an easy, open and integrated circulation of data collected, and an easy use of them by all those who in different ways are called to work on the building.

\subsection{Two-Dimensional GIS for Conservation Activities}

GIS are today the most agile tool for collecting, manipulating, grouping and managing the various data on buildings, allowing to cross-relating $2 \mathrm{D}$ representation (plans, fronts, sections) with information collected in database (i.e. metrical, material, historical, description) [8]. It's infact necessary that detailed knowledge of architectonic heritage must be based on data gathered with a systematic, unified process, with increasing degrees of detail, to provide information on buildings and structures that is as widely sourced and comprehensive as possible. Many GIS for conservation allow also to deduce the cost of the project starting from detail data and mapping of two dimensional drawings. 
In particular in Italy, recently, after the agreement between State and Regions, stipulated in 2001 [9], were created a lot of regional GIS for cultural heritage, both for gathering information on the state of the building and sometimes for the management of the restoration processes and activities. The most interesting and up to date initiatives were made with the aim of singling out a common precept that reveals each system's capacity to meet several objectives which are: on one hand, to create significant content that is as broad ranging as possible, in line with adequate cognitive standards (not only complying with the parameters of the Italian "Istituto Centrale per il Catalogo e la Documentazione" - ICCD - but based on the need for properly executed heritage conservation work) [10]. On the other hand, GIS for built heritage were made with the aim to develop a fully implemented and interoperable tool to support conservation activities, which can be integrated with the tools deployed in everyday planning procedures.

At national level, Italian "Ministero per i Beni Culturali e Ambientali", is developing and increasing the national GIS catalogue of architectonic heritage, called "Sistema Informativo Generale Catalogo (SIGEC)" [11], and is promoting between professionals the use of GIS tools to collect data on conservation activities (i.e. "Sistema informativo per la documentazione georeferenziata in rete dei cantieri di restauro" SICaR) (Fig.2) [12]. But, at the moment, all this kind of important instruments support only $2 \mathrm{D}$ representation and consequently allow to connect various descriptive information only to bi-dimensional shapes of elements and architecture [13] [14].

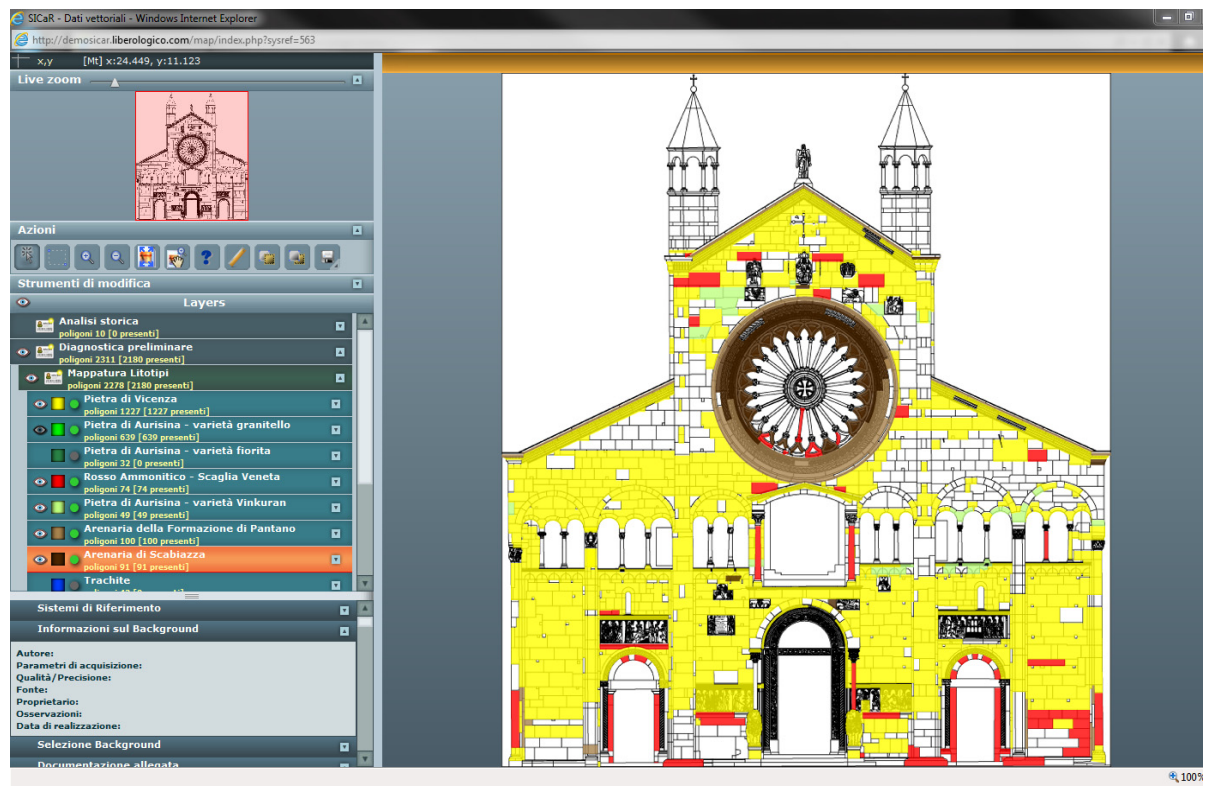

Fig. 2. Example of SICaR for data management of restoration activities on the stone elements of Dome of Modena (collaboration with Università degli Studi of Parma). Different layers and different pattern are associated to different thematic and diagnostic information, in a 2D GIS. 


\subsection{International Spatial Data Infrastructure for Architectonic Heritage}

When speaking of heritage preservation and maintenance it is pretty hard to refer to a single methodology for recording and documentation practice: survey of a site or a building requires a correct documentation and data organisation in order to obtain an Spatial Data Infrastructures (SDI), adequate for all communities dealing with heritage [15] [16] [17]. To provide standards and indications for such a variety of cases an in order to promote data sharing, a national spatial heritage information system (GIS) needs to be defined in accordance with international standards.

As far as geo-spatial information is regarded at international level, the main indications are given by Open Geospatial Consortium (OGC). More particular, the main requirements for spatial information in Europe, are given by the EU SDI community: (i) data harmonization, (ii) real data interoperability, and (iii) data availability and access. Legislative framework is in this sense essential in order to ensure the homogeneous information structuring and sharing across countries, as different data typologies and sets, might exist. The EU Directive on Infrastructure for Spatial Information in the European Community, INSPIRE directive, (2007) [18] has as the major objective to set up a systematic method of coordination between data providers and users in order to gather information and knowledge at different levels. In addition, the European scientific community stresses upon the need of Metadata for Architecture Context (MACE Project, 2008) and it defines concepts of "traditional content metadata and ontologies, context metadata, usage related metadata and metadata acquired though social interaction", in the direction also of the fragmentation, reliability and longevity of the data.

\subsection{Three-Dimensional Content Models}

A step forward in the representation of historic buildings for conservation activities is the use of $3 \mathrm{~d}$ content models. They allow to immediately perceive the building, its volumes and the link between the different structural elements. Nevertheless building a 3D detailed model is a complex and expensive process that requires high competence and capabilities, also in using different modelling software [19] [20]. Infact the elaboration of accurate and realistic 3D content models of historic buildings is certainly strictly related to the requirements regarding the intervention planned; but, in order to be really useful to the professionals in field, the model cannot be only a 3D surface model [21] [22], but it must take into account the geometric laws of construction, the thickness of the walls, the materials, the organisation of elements and the different construction period of every part of the structure [23].

The investigation of the old buildings and their constructive techniques starts from the observation of the existing, moving gradually trough survey towards the virtual reconstruction of the historic structures. This approach aims to generate a dynamic interpretative model, to define control attention thresholds and to identify the soils of risk respects to the structural and environmental stresses, in order to support analysis, simulations and retroactive control [24]. 
However traditional 3D models of built heritage require the connection between the shape of the elements and thematic information collected in a database, in a manual way [25], as represented in image below (Fig. 3). The literature on that argument report few application of 3D GIS for built heritage, almost exclusively territorial-city scale, but not at building scale. With traditional instruments of representation and data gathering is infact very difficult to obtain satisfactory results and articulated 3D models.
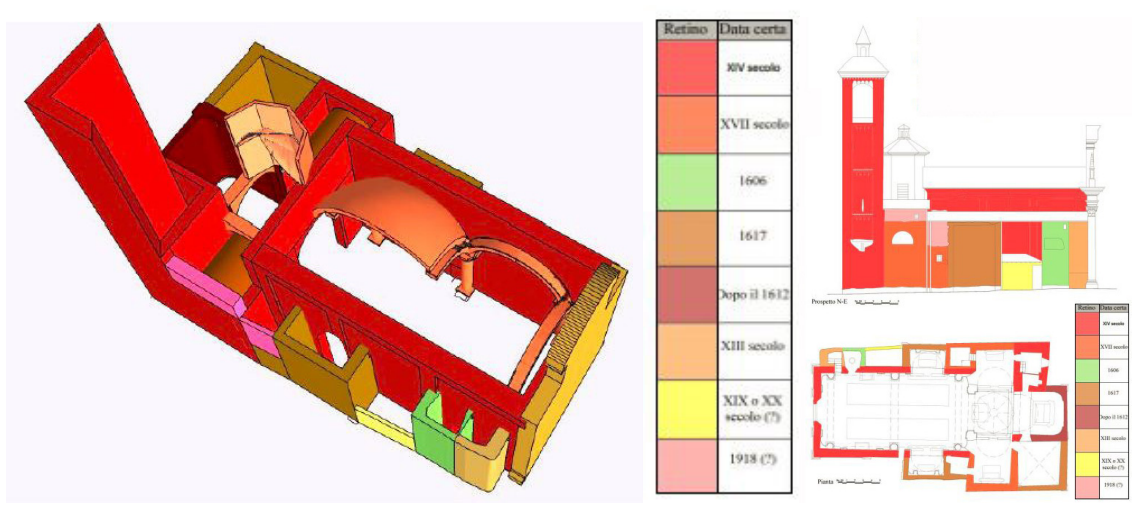

Fig. 3. On the left, 3D schematic content model of Church Saint Maria Assunta of Puria in Valsolda (Como- Italy), obtained elaborating laser scanner (Leica HDS6000) point clouds (CLeica Geosystems HDS Cyclone, @Leica CloudWorks for AutoCAD) with @Autodesk AutoCAD and (CAutodesk 3ds Max. The different colours (legend, in the middle) indicate the different historic phases of construction of the various part and elements of the church.

\section{Toward 3D HBIM for Management and Conservation of Built Heritage}

HBIM is a recent tree-dimensional parametric representation solution to draw [26], model and manage data on historic architectural elements, in a unique software. In particular, this tool allows to combine content information on buildings with data derived from the use of highest technologies of survey (i.e laser-scanner point clouds, 3D models, digital orthophoto, monitoring data), in order to obtain a 3D model in the form of a georeferenced spatial information structure [27]. Therefore BIM software, first used to manage new building construction [28] [29], represent nowadays an opportunity for heritage documentation and conservation management but requires a methodological discussion and practise experimentation to obtain detailed 3D models of irregular historical objects, really useful for their preservation and maintenance activities.

\subsection{Toward a Library of Historical BIM Objects}

Parametric BIM are related to data collected in a database and every change of a parameter causes a change in the shape of the elements [30] [31]; but, at the moment doesn't exist, a shared library for historical elements. The necessity of the libraries 
implementation requires to develop methodologies and algorithms to use data survey, especially point clouds, and to model in BIM software [32] [33] [34], without an oversimplification of the shapes. As a consequence it's essential to think about the level of detail and simplification of the models useful for conservation project, related to the real possibility to modify the parameters of the shape of the architectonic elements, in particular, of historical object that are often irregular, in a isotropic manner.

The literature concerning HBIM illustrates how can be constructed a library of interactive parametric object [35], principally starting from historical dimension given by architectural pattern books [36] [37]. According to this aim, the individuation of shape grammar and stylistic rules can be used to build a first library of historical elements of built heritage. Different kind of architectonic manuals are used to obtain dimensions, proportions and information on geometrical construction [38].

Aim of these researches is to focus the attention on the construction of libraries of architectural elements starting from their survey, using not only laser scanner data (Leica HDS6000, Faro Focus 3D CAM2) but also measures surveyed with traditional instruments [39]. This solution allows both to build an abacus of local constructive element and to compare the real dimensions of the elements with the information derived from architectural pattern books. The aim is to detail the models according to the specific situations.

\subsection{International Indication for Sharing and Open HBIM Libraries}

The International Framework for Dictionaries (IFD) is a mechanism that allows the creation of multilingual dictionaries or ontologis in many research fields. The Data Dictionary is one of the core components also of the buildingSMART technology, [40]. The dictionary, named IFD Library, is a reference library intended to support improved interoperability in the building and construction industry. IFD Library provides a flexible and robust method of linking existing databases with construction information to a buildingSMART based Building Information Model (BIM).

Given that the IFD defined inside the BIM software aren't exhaustive for the Historical Building domain, the definition of dictionaries inside the Historical Building Framework (H-IFD) aims to contribute to create an open DB, updatable, dynamically adaptive to the real context and multi-faced contents of the historical architectures. Once progressively defined HBIM object libraries, Informative System developed to support planned conservation activities could be implemented and integrated within the H-IFD libraries in order to share common vocabularies. Indeed, in order to allow a wide user platform, the definition of such libraries need to get an high level of interoperability between different BIM platform.

To this aim buildingSMART open platform, has developed a common data schema that "makes possible to hold and exchange data between different proprietary software applications. The data schema comprises information covering the many disciplines that contribute to a building throughout its lifecycle: from conception, through design, construction and operation to refurbishment or demolition". Industry Foundation Classes, IFC, are the main buildingSMART data model standard. The IFC 
open format is registered by ISO as ISO/PAS 16739 and is in the process of becoming an official International Standard ISO/IS 16739.

\subsection{Geometrical and Structural Data Interpretation for HBIM Construction of Historical Built Heritage: Case Studies}

In the research, in progress, are compared two different BIM software platforms, (C)Autodesk Revitt and CGrphiSoft ArchiCAD, in particular concerning the possibility to model irregular objects. A lot of case studies regard the construction of HBIM of historical bricks vaults, widely used in north of Italy to cover the rooms of traditional architecture. The survey of many structural elements, grouped for typologies, geometries and age of construction, showed a lot of significant differences in the textures, the dimensions of the elements, the whole shape and the materials; consequently the necessity to use HBIM to models this structures, starting from the real dimension, goes in the direction of valorization of the differences, depending from local traditional constructive technologies. In a logic of BIM construction for conservation, it's however necessary to find a compromise in modelling in order to create a shared library of those kind of elements, whose general drawings could derive from historical architectural pattern. This is a kind of approach that asks a continuous change from general to specific and detail, in a progressive deeper process of knowledge and management of built heritage.

Export test of the geometry (Single Components and Space Boundaries/Room) are on course in order to verify the complete interoperability between the different software using gbXML or IFC format file. This is the only guarantee to allow to other users to adapt 3D modelled elements, with parametric definition, to their specific objects.

Finally is to consider the potential in using HBIM for conservation process because it's possible to deduce the cost of the different activities directly in the software and, modifying the quantity and the dimension of the element is directly possible to manage the variation of the cost during the process. More is detailed the model and more will be precise the cost estimate.

- "Rotonda Besana" in Milan: rib brick vaults. Rib vaults cover the four principal and secondary exedras of the complex of the "Rotonda of Besana" (17131725), once the church and cemetery of the "Ospedale Maggiore" of Milan, dedicated to Saint Michele. Apparently they seemed related to a simple spherical implant, cut by the inscribed trapezium, as usually represented on the related historical documents; however, the analysis of the horizontal, transversal diagonal and longitudinal slices extracted from the point clouds (Leica HDS6000), acquired by different position, have shown a complex ovoid shape, with different directions of the brick block disposition along the same constructive ring (Fig.4). The HBIM of the vaults have been generated (CGraphiSoft ArchiCAD) on the hypothesis of the most probable brick block texture respect to the geometric shape obtained from the laser scans, because of the impossibility to access to the extrados. 
The construction of the 3D models of vaults and their brick elements, requires always a deep geometrical analysis and interpretation of the shapes in order to reproduce them virtually with BIM software and to add geometric and constructive content to three-dimensional model, in particularly on ancient construction technologies and their installation. In this case the chain between the historical analysis of the construction typologies of the vault systems and the real assessment of each element need to be punctually considered, and it requests an high attention to a systematic analysis to verify the hypnotized structures, also using historic architectonic manuals. According to this aim HBIM guarantees the necessary flexibility that often characterized the time-delayed and progressive phases of diagnostic analysis on built heritage trough the possibility to change the parameters in function of future new investigation.

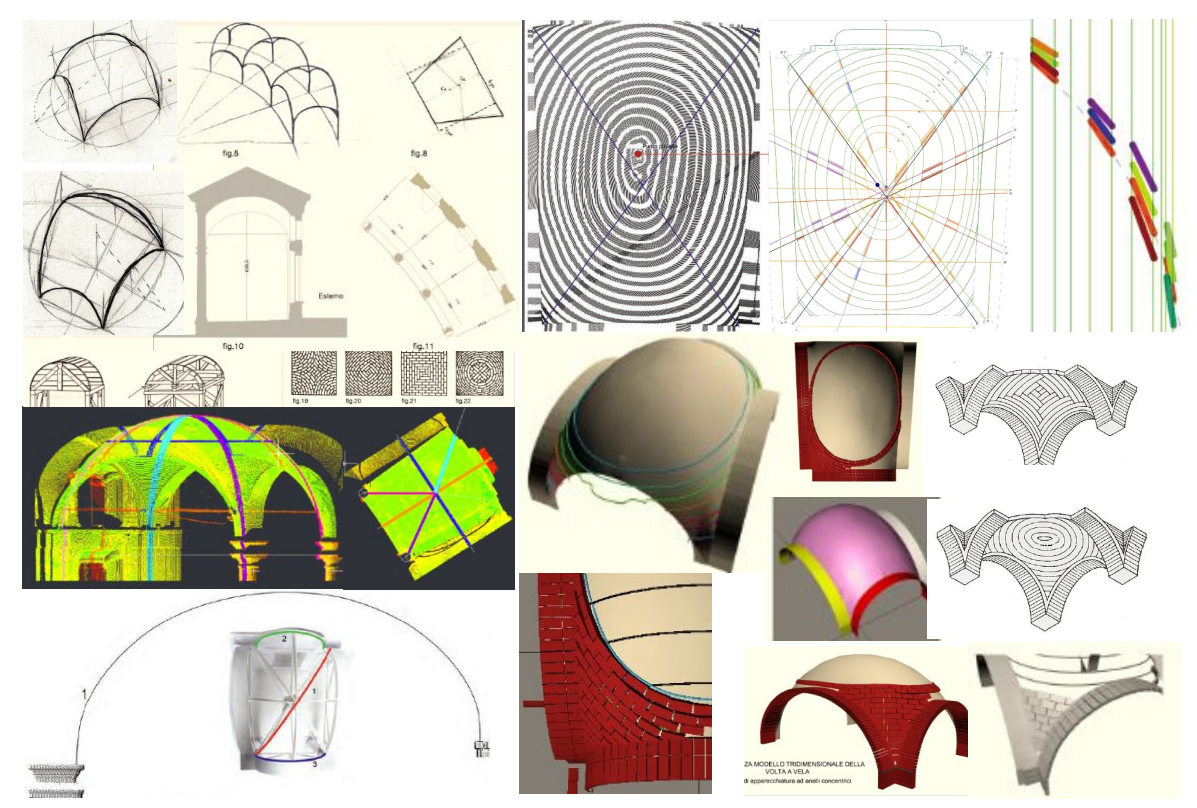

Fig. 4. In the methodological path is reconstructed the geometry of the vault inscribed within the trapezium and the result of an ovoid non spherical shape. The 3D HBIM was generated from laser scanner vertical and horizontal slices (medium accuracy of laser scanner points cloud, $1 \mathrm{~cm}$ ), and the hypothesized texture of the brick block (@GraphiSoft ArchiCAD). Historic architectonic pattern were used to deduce information on the ideal textures and to compare it with the real geometry of the vault.

- $\quad$ Saint Maria Church in Scaria d'Intelvi (Como - Italy): The Church of Saint Maria has a complex constructive history and its structures were expanded and transformed in decoration more times along the centuries. The high resolution laser scanner survey allowed to model the three vaults that cover the ceiling of the church and to deduce some important information on different stratigraphic phases of construction and on historical use of the centrings. 
Previous surveys and first observations of the two nave vaults suggested a unique similar shape and geometry of them, but the will to build a precise 3D model obliged to investigate in detail the real geometry of the vaults, extracting from point clouds different section at different level (horizontal and vertical). Through this process of data survey elaboration was possible to underline the differences between the shapes of the two vaults, probably derived from the use of a unique centrings, irregular in its profile, that was moved to build the second vaults, once built the first (Fig. 5).

In addition, the analysis of the disposition of the bricks from the extrados allowed to build a HBIM without supposing any elements but using real dimensions to associate material information. Three-dimensional model was completed in every part and elements and historical information were associated to each one in order to obtain a HBIM of the whole church.
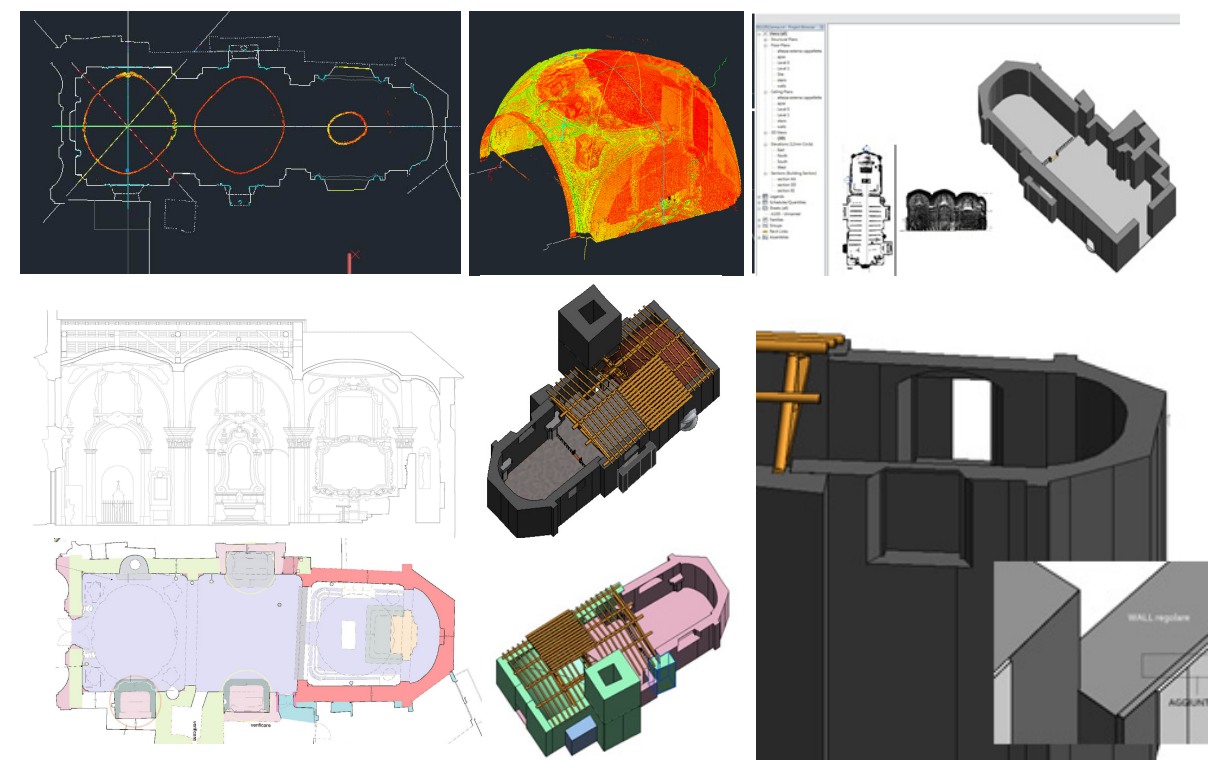

Fig. 5. (Left) Plans and longitudinal section of the church with laser scanner point clouds of one of the vaults: it's evident the same irregular shape of the two first vaults, caused probably from the rotation of the wooden centrings. (Right) HBIM (@)Autodesk Revitt) of the church; the different colours in the plan and in the $3 \mathrm{~d}$ model indicate the different constructive phases derived from the cross-relation of historical data and surveying data interpretation.

\section{- $\quad$ Soldi Palace in Cremona (Italy): Wooden Vautls}

The origin of the first part of Soldi palace dates XVth century and it was built as a noble residence. During the following centuries the palace was expanded and many rooms were covered with bricks or wooden vaults, as usual in this region. In particular it was interesting analyzed, surveyed and modelled a pavilion wooden vault that cover a room of the main floor of the building. The possibility of inspecting the extrados of the vault allowed to measure every layer of the structure and to create a 
detailed HBIM model of the element (Fig. 6). The textures, the materials and their state of conservation was investigated in detail and all the data reported in the HBIM. The geometrical model were created using (CAutodesk AutoCAD and Revit to elaborate the laser scanner (Faro Focus 3D) points clouds of the intrados of the vault (precision $\approx 1 \mathrm{~cm}$ ) and measuring with traditional instruments the extrados. The exact shape of the cloister vault were created starting from the extraction from the points cloud of the two slices corresponding to longitudinal and transversal section of the structural element. A cloister vault is infact the result of the crossing of two barrel vaults and to obtain a correct structural model is necessary starting from the constructive process of building; this method is in accordance with the idea of a BIM, to model the building per elements and not per surfaces. In architecture and in particular in modelling for conservation is infact fundamental to consider the building as a sum of structural elements (with their thickness, materials and so on) and not as an ensemble of many precise surfaces, as unfortunately is normally done yet. 3D surfaces representation of built heritage are useful for tourism, promotion, or virtual paths but not for conservation projects.

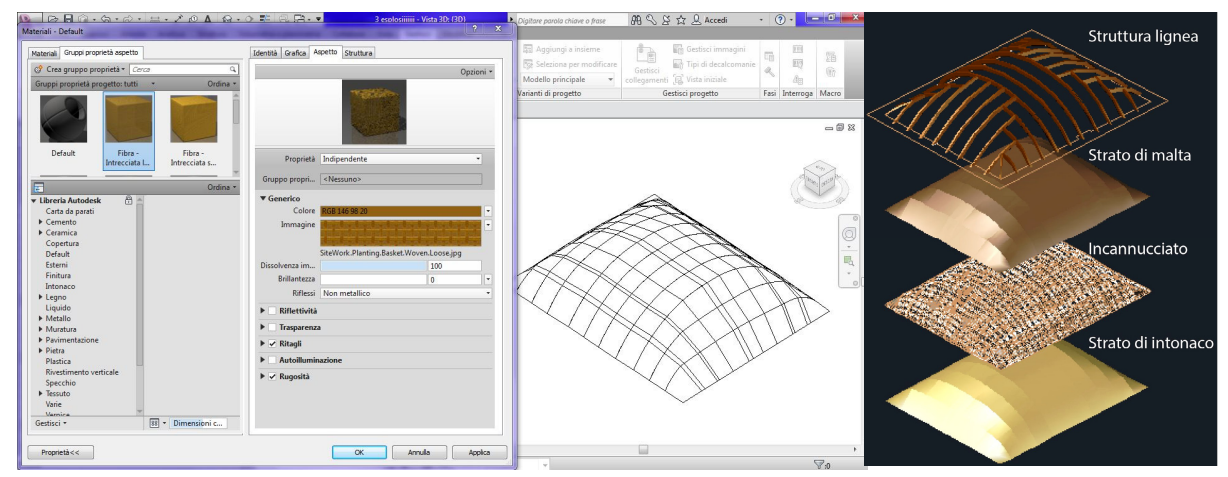

Fig. 6. HBIM (CAutodesk Revit) of wooden vault in Soldi Palace in Cremona (Italy): 3D elements modelling process using laser scanner point clouds and hands on measures. Information on architectonic elements materials and their stratigraphy are indicated in the database, together with geometrical data.

\section{Conclusions}

HBIM is based on simplified parametric models, suitable for industrial elements and modern architecture, while further investigation should be done in order to apply this kind of documentation in a broader heritage conservation practices.

The case studies show how could be possible to experiment and verify the transition from the concept of surface towards object representation, supporting enhance the comprehension of the single elements within the model information of the overall building organism, and allow the connection to descriptive thematic database (constructive technologies, elements abacus), in a logic of semantic content models. 
These kind of three-dimensional detailed virtual models are useful instrument for improving remote access to data that could provide support to advanced programs for preventive conservation and guarantee sustainable interventions and maintenance over time; moreover they can be able to host both geometrical - historical survey data and materials or degradation information. In particular, the possibility of building three-dimensional models of ancient vaults, of high geometric precision and that take into account the exact thickness of the walls, the materials and the disposition of the elements, allows to support complex analysis on the state of maintenance of the buildings and on the stability of their structures. In fact, through an accurate 3D survey of the structures it is also possible to get all the basic geometric data to derive information on the constructional genesis of the elements and on the constructive methodologies used in the past. These are basic information useful to evaluate the structural behaviour of the vaults, together with the identification of geometrical anomalies in the structures, crushing and implosion areas.

HBIM libraries implementation for built heritage elements requires a wide and shared research on drawings, elaboration and interpretation activities of data survey: consequently it's necessary that this aim is shared as much as possible between the expert in documentation and representation of the built heritage.

\section{References}

1. Cooperative Research Centre for Construction Innovation: National Guidelines for Digital Modelling, Brisbane, Australia (2009)

2. Eastman, C., Teicholz, P., Sacks, R., Liston, K.: BIM Handbook. A guide to Building Information Modeling for Owners, Managers, Designers, Engineers, and Contractors. Jonn Wiley \& Sons, Hoboken (2008)

3. Recording, Documentation, and Information Management for the Conservation of Heritage Places. The Getty Conservation Institute, Los Angeles (2007)

4. Cuca, B.: PhD Thesis. Communicating the cultural heritage using Photogrammetry. 'Box systems' for spatial data within virtualized environments as a methodology for preventive conservation and maintenance. Politecnico di Milano, Milan, Italy (2010)

5. Petzet, M., Mader, G.: Praktische denkmalpflege. In: Kohlhammer, W. (ed.), Stuttgat Berlin Köln (1995)

6. Remondino, F., Rizzi, A., Barazzetti, L., Scaioni, M., Fassi, F., Brumana, R., Pelagotti, A.: Review of geometric and radiometric analyses of paintings. The Photogrammetric Record 26, 439-461 (2011)

7. Della Torre, S.: La conservazione programmata del patrimonio storico architettonico. Linee guida per il piano di manutenzione e consuntivo scientifico. Guerini, Milano (2003)

8. Oreni, D.: PhD Thesis. Knowledge and conservation of the built heritage. Cataloguing and geographic information system. Politecnico di Milano, Milan, Italy (2008)

9. Sessa, V.M.: L'accordo Stato-regioni in materia di catalogazione dei beni culturali. Aedon. Rivista di Arti e Diritto Online n. 2 (2001),

http://www aedon.mulino.it/archivio/2001/2/sessa.htm

10. http://www.iccd.beniculturali.it/index.php?it/115/ standard-catalografici

11. http://www.iccd.beniculturali.it/index.php?it/118/ sistema-informativo-generale-del-catalogo-sigec 
12. http://sbap-pr.beniculturali.it/index.php?it/180/ progetto-rearte-sicar

13. Brumana, R., Prandi, F.: Use of 3D GIS to Model Urban environment. In: Proceedings of Urban and Regional Data Management, UDMS 2007, pp. 223-230. Taylor and Francis Group, London (2008)

14. Prandi, F., Brumana, R.: Semi-automatic Objects Recognition Process Based on Fuzzy Logic. In: Sithamparanathan, K., Marchese, M., Ruggieri, M., Bisio, I. (eds.) Psats 2010. LNICST, vol. 43, pp. 343-353. Springer, Heidelberg (2010)

15. Brumana, R., Oreni, D., Cuca, B., Rampini, A., Pepe, M.: Open Access to Historical Atlas: Sources of Information and Services for Landscape Analysis in an SDI Framework. International Journal of Agricultural and Environmental Information Systems (3) (in press July 2013)

16. Brumana, R., Oreni, D., Cuca, B., Rampini, A., Pepe, M.: Open Access to Historical Atlas: Sources of Information and Services for Landscape Analysis in an SDI Framework. In: Murgante, B., Gervasi, O., Misra, S., Nedjah, N., Rocha, A.M.A.C., Taniar, D., Apduhan, B.O. (eds.) ICCSA 2012, Part II. LNCS, vol. 7334, pp. 397-413. Springer, Heidelberg (2012)

17. Oreni, D., Brumana, R., Cuca, B.: Digital Cartographic Heritage in Service to the Society: Landscape Analysis for Informed Decision Making. In: Virtual Systems in the Information Society, NJ, USA, pp. 499-506 (2012)

18. INSPIRE EU Directive: Directive 2007/2/EC of the EU Parliament and of the Council establishing an Infrastructure for Spatial Information in the EU Community. Official Journal of the European Union, L 108/1(50) (14 March 2007),

http: / / eur-lex.europa.eu/

JOHtml.do?uri=OJ : L: $2007: 108$ : SOM : EN : HTML (April 25, 2007)

19. Brumana, R.: Sant'Ambrogio's Basilica in Milan. A study on photogrammetric surveys in the S. Vittore in Ciel d'Oro's dome. In: Proceedings of SPIE - The International Society for Optical Engineering, vol. 1395, pp. 908-915 (1990)

20. Brumana, R., Crippa, B., Vassena, G.: Analytical treatment and description of the altimetric check of the St. Marcus'Basilica in Venice. In: Proceedings of SPIE - The International Society for Optical Engineering, vol. 1395, pp. 166-173 (1990)

21. Remondino, F., Niederoest, J.: Generation of high resolution mosaic for photo-realistic texture - mapping of cultural heritage 3D models. In: Arnold, D., Chalmers, A., Niccolucci, F. (eds.) Proceedings of the 5th International Symposium on Virtual Reality Archaeology and Intelligent Cultural Heritage, VAST 2004, pp. 85-92 (2004)

22. Nex, F., Rinaudo, F.: Multi-image matching: an "old and new" photogrammetric answer to lidar techniques. In: Chen, J., Jiang, J., Maas, H.G. (eds.) Proceedings of International Society for Photogrammetry and Remote Sensing, Beijing, China, vol. XXXVII/B5, pp. 621-626 (2008)

23. Oreni, D., Brumana, R., Cuca, B.: Towards a Methodology for 3D Content Models. The Reconstruction of Ancient Vaults for Maintenance and Structural Behaviour in the logic of BIM management. In: Virtual Systems in the Information Society, NJ, USA, Milan, Italy, pp. 475-482 (2012)

24. Oreni, D., Cuca, B., Brumana, R.: Three-dimensional virtual models for better comprehension of architectural heritage construction techniques and its maintenance over time. In: Ioannides, M., Fritsch, D., Leissner, J., Davies, R., Remondino, F., Caffo, R. (eds.) EuroMed 2012. LNCS, vol. 7616, pp. 533-542. Springer, Heidelberg (2012) 
25. Santana, M.: PhD Thesis. The use of three-dimensional documentation and dissemination techniques in studying built heritage. R. Lemaire International Centre for Conservation, Catholic University of Leuven, Belgium (2003)

26. Cooperative Research Centre for Construction Innovation: National Guidelines for Digital Modelling. Brisbane, Australia (2009)

27. Pauwels, P., Verstraeten, R., Meyer, R.D., Campenhout, J.V.: Architectural Information Modelling for Virtual Heritage Application, Digital Heritage. In: Proceedings of the 14th International Conference on Virtual Systems and Multimedia, Archeolingua (2008)

28. Lee, G., Sacks, R., Eastman, C.E.: Specifying parametric building object behaviour for a building information modelling system. Automation in Construction 15(6), 758-776 (2006)

29. Eastman, C., Teicholz, P., Sacks, R., Liston, K.: BIM Handbook. A guide to Building Information Modeling for Owners, Managers, Designers, Engineers, and Contractors. Jonn Wiley \& Sons, Hoboken (2008)

30. Boeykens, S.: Using 3D Design software, BIM and game engines for architectural historical reconstruction. In: CAAD Futures, Liege, Belgium (2011)

31. Boeykens, S., Himpe, C., Martens, B.: A case study of using BIM in Historical Reconstruction. The Vinohrady synagogue in Prague. In: Proceedings of the 30th International Conference on Education and Research in Computing Aided Architectural Design in Europe, Prague, Czech Republic (2012)

32. Murphy, M., McGovern, E., Pavia, S.: Historic Building Informatio Modelling. Adding intelligence to laser and image based surveys of european classical architecture. ISPRS Journal of Photogrammetry and Remote Sensing 76, 89-102 (2013)

33. Chevrier, C., Charbonneau, N., Grussenmeyer, P., Perrin, J.P.: Parametric documenting of built heritage: $3 \mathrm{D}$ virtual reconstruction of architectural details. International Journal of architectural Computing 8(2), 131-146 (2010)

34. Chevrier, C., Maillard, Y., Perrin, J.P.: A method for the 3D modelling of historic monuments: the case of a gothic abbey. In: ISPRS International Archives of Photogrammetry. Remote Sensing and Spatial Information Science, vol. 38 (5/W1) (Cdrom), Elsevier (2009)

35. Tang, P., Huber, D., Akinci, B., Lipman, R., Lytle, A.: Automatic reconstruction of asbuilt building information models from laser-scanned point clouds. A review of related techniques. Automation in Construction 19(7), 829-884 (2011)

36. Fai, S., Graham, K., Duckworth, T., Wood, N., Attar, R.: Building Information Modelling and Heritage Documentation. In: Proceedings of the 23rd International Symposium, International Scientific Committee for Documentation of Cultural Heritage, CIPA, Prague, Czech Republic (2011)

37. Fai, S., Duckworth, T., Graham, K., Wood, N.: Building Information Modelling and the Conservation of Modern Heritage. In: Proceedings of the 24th World Congress of Architecture, Union International des Architects, UIA, Tokyo, Japan (2011)

38. Dore, C., Murphy, M.: Semi-automatic modelling of building facades with shape grammars using historic building information modelling. In: ISPRS International Archives of Photogrammetry, Remote Sensing and Spatial Information Science, vol. XL (5/W1) (Cdrom). Elsevier (2013)

39. Brumana, R., Oreni, D., Cuca, B., Binda, L., Condoleo, P., Triggiani, M.: Strategy for integrated surveying techniques finalized to interpretive models in a byzantine church, Mesopotam, Albania. International Journal of Architectural Heritage (2013) (accepted on publishing)

40. http://www.buildingsmart-tech.org/ 